\title{
Research on the Influence of We-Media News Dissemination on Traditional News Communication
}

\author{
Liang Liwei \\ Weinan Normal University, Weinan, Shaanxi, 714099
}

Keywords: We-media, News Communication, Traditional Media

\begin{abstract}
Newspapers, broadcasting and other traditional news media have no effect in the past information dissemination. After decades of development, the form of traditional news media has matured, whether technology, equipment or talent reserves are very perfect. With the development of information network technology and intelligent terminal technology, various kinds of information media are springing up. All kinds of media platforms can publish news at anytime and anywhere. Since the media is a kind of new information platform with a variety of features, the video, text, audio, images and other forms of information are integrated into one, to spread the use of information network technology, to ensure the timeliness and richness of news to the maximum extent. Under such circumstances, traditional news communication is bound to be strongly impacted. How to quickly adapt to the era of we-media and realize the organic combination of traditional news communication and we-media is an important topic before traditional news communicators.
\end{abstract}

\section{The Connotation of News Communication between the We-media and the Traditional Media}

\subsection{The connotation of traditional media}

Traditional media is a concept relative to the network media. It refers to the media that regularly publish news and information and provide educational and entertainment activities through a mechanical device. The traditional media include common newspapers, magazines, radio, TV and so on. Such media organizations mainly collect, select, process and transmit information [1]. Compared with the network information platform, the traditional media have more specialties, and these media organizations have large scale of production and wide audience, so they are also called mass media. Thus, the traditional media embodies two characteristics, one is the social organization as a professional driver in the unified organization goal, organization doctrine under the dissemination of news reporters and editors, and other professional journalists engaged in related information dissemination work in different departments perform their respective duties [2-3]. And its difference with the media is the largest, is directly related to all kinds of news practitioners and their subordinate units of occupation behavior, do not belong to their personal behavior. On the other hand, mass media production is controlled by traditional media, needs the support of advanced technology in the production process of news and information, including expensive production machines and equipment, and media organizations directly using these technologies and equipment for the dissemination of information, in order to meet the desire of consumer information, especially in some important media resources also by the state in some form of control.

\subsection{The connotation of we-media}

Since the media is a use of network technology, the Internet platform as the basis for the general public for real-time release, exchange and sharing a platform for information dissemination, and issued by the general public can be the social news, can also be their own experience, can also be found themselves interested in the news. Since the media links global knowledge through digital technology, its main forms include blogs, micro-blog, online video podcasting, social networking and so on, such as Youtube and Twitter commonly used abroad, and commonly used WeChat, Sohu blogs, Renren, knowledge and so on [4]. The user can real-time we-media platform to publish text, 
pictures and video news information related information, compared with the traditional media, since the media convenient advantage is very outstanding, and may even form a strong network public opinion and the impact of traditional media, government decision-making [5]. The ubiquity of network technology provides reliable technical support for the development of media. Since the media has strong communication function and rich content form, it has stimulated the desire of netizens to express their desires and is becoming an important way to influence people's lives. Even some scholars believe that the media has broken through the scope of the media and has become a new system of discourse.

\section{The Influence of the We-Media on the Traditional News Transmission}

As a new mode of news dissemination, the influence of the media on the traditional media is very profound. In particular, it is mainly reflected in the following aspects:

\subsection{Influence on traditional news traditional objects}

In the era of Internet, the form of social media is more and more diverse, which strongly impacts the traditional media industry. Traditional news communication is facing great challenges, which has the most significant impact on the role of disseminators and communicators. For example, in the traditional media, news and events must be reviewed and checked strictly, and through traditional media such as broadcast and television spread to a wide audience, the audience may also by word of mouth information [6]. In the era of media, news communicators not only play the role of news and information transmitter, but also play multiple roles such as audience, information publisher and so on, that is, news communicators themselves may also be parties to a news event. Since the era of media, the integration of news information and audience has been possible, breaking the barriers between the communicator and the audience in traditional journalism and communication mode, expanding the scope of news communication and enhancing the social effect of news events. In short, media news communication has strengthened the authenticity and validity of news events from a certain perspective, thus further enhancing the individual's understanding of the connotation of news information [7].

\subsection{The impact on the content of the news}

The traditional way of news communication is a relatively closed process. The information content that audiences receive is often filtered and released under specific restrictions. Since the media is in an open environment, both the news material and the news content are relatively open, and this openness will have a strong impact on the relatively closed traditional media. Since the content of media news is closely related to the public, its content is more close to the life of the audience [8]. It has a certain representativeness and can produce more resonance with the public. Therefore, the integration of news and we-media has increased the audience of news information. And the news content which is spread by the media is consistent with the guidance of public opinion, and also provides greater space for the dissemination of news. Influenced by the management mechanism, traditional media cannot guarantee the effectiveness of news information in many cases, and the media platform can provide many live news at the first time, which will also greatly affect the traditional news communication.

\subsection{The influence on the standard of judging the values of the news}

The traditional mode of news dissemination, freshness, importance, authenticity, interest, significant and real-time are the main factors to evaluate the value of news information, but from the media environment that people tend to focus on more fresh and interesting news and ignore other factors; and the traditional journalism and communication is relatively that way, even if the audience for a news content to have their own ideas, but also impossible to express personal views, and the value of news content with the editor view, the audience's opinions have been suppressed. From the media age, the audience can freely express their views and values on the network platform, greatly enriching the richness and diversity of news dissemination, and making news transmission 
more close to the public's life [9].

\section{The Integration of Traditional News Communication and We-Media in the Era of Media}

In view of the impact of we-media on traditional journalism and communication, traditional news communication should face up to its own problems and strengthen its integration with the media, in order to better adapt to the development of the times.

\subsection{Changing the traditional form of communication}

The traditional news propagation mode is a linear form of media, the flow of information is relatively one-sided, upstream of news communication in the news information, and then through the carrier of newspapers and magazines, radio and television media flow to the downstream of the audience, since the emergence of the media is the subversion of the traditional form of journalism. Spread in the form of a traditional linear type is gradually replaced by the form of interactive communication, and gradually occupy the dominant position. Compared with the traditional linear, one-way media, since the media is a point to point communication, the communicator and the audience no clear boundaries, anyone can through the intelligent terminal and others for information sharing and interaction, and the propagation behavior is not affected by time and region limit, is a highly circular forms of communication [10]. Therefore, traditional media should constantly expand their own information distribution channels, strengthen contacts and interactions with audiences, and improve the diversification and transparency of news information, so as to improve the stickiness and activity of news information. The traditional media from the media to use the advantages, through the Internet to open up new business and new markets, the construction of the official website, open micro-blog, forum and other forms of communication channels, strengthen the interaction with the network audience; and use the power of the Internet to find news clues, the network interview; also for emergencies, timely update and report the use of the network, to ensure the effectiveness of the news, to do more articles in the breadth and depth of the news.

\subsection{Expanding the concept of traditional news disseminators}

The spread of news dissemination in the traditional usually is a journalist, editor, commentator, host, announcer and other professional journalists, the professional media organizations set up by professional threshold makes do not have the professional knowledge and news literacy of ordinary people can not act as news communicators. The development of Internet technology to promote changes in the mode of information dissemination, network information transmission has the characteristics of convenience, easy operation, low threshold, so that ordinary people can also participate in the news production and dissemination to a variety of network media platform so that ordinary people to the public dissemination of the news and information gathering [11]. The traditional news media organizations should provide more views and opinions platform for ordinary people, ordinary people to improve the initiative in the dissemination of information in nature; guide the general public is more real, more show, in-depth mining of news events, news reports revealed the truth. For example, with making professional cooperation, the provision of paid news clues, or with the well-known network anchor cooperation and so on, in order to expand the influence of news. In addition, to encourage news communicators and audience for different opinions and information on the public platform for interaction and communication, to lead to more collective thinking, so that the views and opinions more scientific and comprehensive, the general news disseminator role into full play.

\subsection{Establishing a sound environment for monitoring the media platform}

Although the news media has many advantages, there still exist some deficiencies. Frequent occurrence of news anomie is a very prominent point. Since the media to lower barriers to entry makes personal editing, news release information of its authenticity, objectivity cannot keep, affecting the quality of media news from the user's personal moral bottom line, media literacy, control of the content of news dissemination in the traditional news media platform does not exist, 
therefore the credibility of the news media needs to be improved, increasing the cost of credit spread from the media news virtually. Therefore, in order to establish a sound environment for monitoring the media platform, the relevant legislature should act immediately, improve relevant laws and regulations, and clean up the environment of Internet public opinion. Such as the implementation of the network real name system, in order to standardize the healthy growth of the new media. Besides, we must rely on the mainstream media to consolidate and deepen the reform of news system, create a good mainstream public opinion environment and create a harmonious socialist society.

\section{Conclusions}

In a word, though the news media has a great influence on the news communication of traditional media, it also promotes the innovation and development of traditional journalism. Traditional media should regard the emergence and development of we-media as an opportunity for innovation. We-media and mainstream media are in the background of today's media convergence, apart from competing with each other, more cooperation should be sought. Only by mutual benefit can they adapt to the trend of the times and spread more and better news for the wide audience.

\section{Acknowledgements}

This thesis thanks from project supported by special scientific research program of the Education Department of Shaanxi province in 2017: "the promotion of Shaanxi culture to spread the stress path of Belt and Road Initiative background (17Jk0261) support.

\section{References}

[1] Weeks B E, Holbert R L. Predicting Dissemination of News Content in Social Media A Focus on Reception, Friending, and Partisanship [J]. Journalism \& Mass Communication Quarterly, 2013, 90(2):212-232.

[2] Dai L, Parwada J T, Zhang B. The Governance Effect of the Media's News Dissemination Role: Evidence from Insider Trading [J]. Social Science Electronic Publishing, 2015, 53(2):331-366.

[3] Buckarma E H, Thiels C A, Gas B L, et al. Influence of Social Media on the Dissemination of a Traditional Surgical Research Article[J]. Journal of Surgical Education, 2017, 74(1):79.

[4] Klinger U, Svensson J. The emergence of network media logic in political communication: A theoretical approach [J]. New Media \& Society, 2015, 17(8):págs. 1241-1257.

[5] Gehrau V, Döveling K, Sommer D, et al. Antagonistic and synergetic impacts of conversation on non-persuasive media effects [J]. Communication Research, 2014, 41(4):578-602.

[6] Pineiro R. E-Electioneering: The Political and Cultural Influence of Social Media in the 2008 and 2012 Presidential Elections [J]. Journal of Yunnan University of Nationalities, 2015, 22(3):423-442.

[7] Moeller J, Vreese C D, Esser F, et al. Pathway to Political Participation: The Influence of Online and Offline News Media on Internal Efficacy and Turnout of First Time Voters [J]. American Behavioral Scientist, 2014, 58(5):689-700.

[8] Holt K, Shehata A, Strömbäck J, et al. Age and the effects of news media attention and social media use on political interest and participation: Do social media function as leveller?[J]. European Journal of Communication, 2013, 28(1):19-34.

[9] Cai L H. On the Dissemination and Influence of Public Self-made Network Video News [J]. Journal of Hubei Vocational College of Ecological Engineering, 2012, 357(3):977-980.

[10] Moeller J, Vreese C D, Esser F, et al. Pathway to Political Participation: The Influence of 
Online and Offline News Media on Internal Efficacy and Turnout of First Time Voters [J]. American Behavioral Scientist, 2014, 58(5):689-700.

[11] Prieler M, Choi J. Broadening the Scope of Social Media Effect Research on Body Image Concerns [J]. Sex Roles, 2014, 71(11-12):378-388. 